\title{
The effects of obesity on outcomes in trauma injury: overview of the current literature
}

Milad Modarresi MD ${ }^{1}$, Brad Gillon MD ${ }^{1}$, Javad Najjar Mojarrab MD, MBA ${ }^{1}$, Rodrigo Aguilar $\mathrm{MD}^{1}$, Zackary Dylan Hunter MD ${ }^{1}$, Matthew Steven Schade MSc${ }^{1}$, Jackie Sanabria BSc ${ }^{1}$, Rebecca Klug MD ${ }^{1}$, Seth Adkins MD ${ }^{1}$, Juan R. Sanabria MD, MSc, FACS ${ }^{1}$

\section{Author Affiliations:}

1. Marshall University Joan C. Edwards School of Medicine, Huntington, West Virginia

The authors have no financial disclosures to declare and no conflicts of interest to report.

\section{Corresponding Author:}

Juan Sanabria MD, MSc, FACS

Marshall University Joan C. Edwards School of Medicine

Huntington, West Virginia

Email: sanabriaj@marshall.edu 


\section{Abstract}

Obesity has reached epidemic proportions and is now considered a chronic disease by the

National Institute of Health (NIH) in the West. Its impact on trauma outcomes is of particular interest with several studies presenting conflicting information. The present overview suggests a strong association between obesity and injury severity, hospital length of stay (LOS), intensive care unit (ICU) admission, pattern of injury, rate of complications and mortality. The nature of the observations may relate to an underlying physiological state of the obese patient and its associated comorbidities with a constant heightened inflammatory state aggravated by the second hit on an injury.

\section{Keywords}

Review, Trauma, Injuries, Obesity, Outcomes

\section{Background}

Obesity has increased in epidemic proportions in the West. Two out of every three adults are overweight and one out of every three adults are obese in the United States. ${ }^{1,2}$ Metabolic and mechanical implications of increased total fat content include dyslipidemias, hypertension (HTN), insulin resistance state and their consequences, coronary artery disease (CAD), cerebral vascular accident (CVA), non-alcoholic steato-hepatitis (NASH), cancer, arthritis, and sleep apnea. These comorbidities can independently, or in association with other conditions, increase morbidity and mortality. Obesity and its impact on trauma outcomes is one of the main topics that has increased in popularity within the past decade although the current data presents conflicting information. The goal of this report is to perform an overview of the current literature and to determine the effect of body mass index (BMI) on trauma injuries.

\section{Methods}

A systematic review was performed using PubMed (https://www.ncbi.nlm.nih.gov/pubmed/). Authors performed the search using key words obesity AND trauma, BMI AND trauma. The search included all pediatrics and adult articles published from January 2005 to February 2017. Case reports and review articles were excluded along with papers covering the psychological effects of trauma on children and also higher BMI during adulthood. The total number of papers that met our inclusion/exclusion criteria was 40 with the majority being retrospective chart reviews.

\section{The effect of obesity on mortality in trauma injury}

Although some studies found no association between obesity and trauma, a cross-sectional study performed by Finkelstein et al. found the odds of sustaining an injury were $15-48 \%$ higher in over-weight and obese patients when compared to other groups. ${ }^{3}$ In addition, Hoffmann et al. demonstrated increased mortality in obese patients suffering from poly-traumatic injury in Germany. ${ }^{4}$ Bochicchio et al. found a 7.1 times increased hospital mortality rate in obese patients following trauma. ${ }^{5}$ Moreover, this group demonstrated a two-fold increase in number of urinary tract, blood stream, and respiratory infections in the obese group. Similarly, Ditillo et al. 
demonstrated that obese patients cataloged in National Trauma Databank had higher mortality after suffering a blunt trauma. ${ }^{6}$ This study matched patients by using propensity score based on age, sex, injury severity score (ISS), Glasgow Coma Scale (GCS), and systolic blood pressure (SBP). In the former report, the obese group had longer hospital length of stay (LOS), intensive care unit (ICU) stay, and morbidity.

Alban et al. monitored the LOS for patients admitted to the surgical intensive care unit following trauma injury. ${ }^{7}$ The ICU length of stay was higher in the obese group, but when regression analyses were performed, no association between BMI and mortality was observed. The former study may have failed to show such a correlation, obesity-to-mortality, due to a selection bias where patients evaluated were those admitted to surgical ICU and not those who expired from trauma either at the scene or emergency room (ER).

Diaz et al. noted morbid obesity was not a risk factor for mortality in trauma patients. ${ }^{8}$ Groups were divided into obese with BMI $>40 \mathrm{~kg} / \mathrm{m}^{2}$ and non-obese with $\mathrm{BMI}<30 \mathrm{~kg} / \mathrm{m}^{2}$. While the study excluded patients with BMI in between $(30<\mathrm{BMI}>40)$, the protocol included only patients admitted to the hospital greater than three days. Patients with high BMI who expired at the scene, during transport, or in the emergency room were not evaluated, thus skewing the data towards no difference in observed outcomes.

\section{The effect of BMI on recovery time in trauma injury}

Obese post-trauma patients may require longer recovery time following a procedure. A study conducted by Childs et al. reported that days in ICU and mechanical ventilation were significantly prolonged in obese patients. ${ }^{9}$ These patients also had a much higher rate of complications such as acute kidney injury (AKI) and infections. Dhungel et al. used functional independence measurement (FIM) to measure the delay in recovery following trauma in patients. ${ }^{10}$ They found that every $1 \mathrm{~kg} / \mathrm{m} 2$ increase in BMI correlated to decrease of $4 \%$ in FIM in obese patients $(\mathrm{P}<0.001)$. Study of trauma patients that needed temporary abdominal closure (TAC) was done by Johnston et al. ${ }^{11}$ LOS in ICU was significantly higher in patients with morbid obesity (BMI $>40$ ) compared to patients with BMI $<25$. They also required longer mechanical ventilation compared to patients with BMI $<18.5$. This study did not find any difference in survival or type of abdominal closure between groups (stratified by BMI). They also concluded TAC can be used safely in trauma patients with BMI $\geq 30$. Hyperglycemia following trauma is a well-known phenomenon, especially in patients suffering head trauma. Bonizzoli et al. studied this phenomenon in trauma patients without head trauma. ${ }^{12}$ After conducting a propensity match to equate groups, they discovered that patients who presented with acute insulin resistance post injury had a significantly higher BMI, C-reactive protein, and leukocyte counts suggesting that monitoring insulin resistance can predict outcomes in the obese patient group.

The rate of associated injuries and complications is increased in the obese patient when compared to non-obese patient with trauma. Decubitus ulcer development and wound complications rose by 4-8 and 2.5-4 folds respectively amongst severely obese patients. ${ }^{13}$ Same 
patients were $30 \%$ more likely to die and approximately two times more likely to have a major complication. Livingston et al. reported obese patients undergoing laparotomy were associated with increased LOS in the ICU as well as increased rates of respiratory and renal failure, bacteremia, and abdominal wound dehiscence. ${ }^{14}$ Nonetheless once logistic regression was performed on their data, BMI was not seen to be an independent predictor for morbidity in this group. Serrano et al. found obesity to be an independent risk factor for pulmonary and wound infections after controlling for variables such as ISS, age, ICU LOS, and multiple comorbidities. ${ }^{15}$

Rhabdomyolysis is one complication that patients may experience after traumatic injury. In a retrospective study done by Chan et al., patients with BMI of 25 and higher, who suffered trauma (especially blunt trauma from MVC), were found to have a significantly higher risk of developing rhabdomyolysis. ${ }^{16}$ As a result, authors recommend aggressive monitoring of creatinine kinase levels in this patient population. Acute kidney injury (AKI) post trauma is one of the most common sources of morbidity and poor outcome in patients. Shashaty et al. published risk factors for the development of AKI included obesity, being of African-American descent, and blood products given. ${ }^{17}$

Obese patients after trauma are at higher risk for deep venous thrombosis (DVT) and possible pulmonary embolism (PE), which could lead to an increase chance of mortality. Patients following trauma have shown to be at a hypercoagulable state. Kornblith et al. conducted a prospective study to evaluate clotting factor levels in obese patients post injury. ${ }^{18}$ They found significantly higher platelet counts at times of admission as well as higher levels of factor IX, but lower D-dimer levels. Clot strength and functional fibrinogen levels were also higher in obese patients. Using regression logistics, they found for every $5-\mathrm{kg} / \mathrm{m}^{2}$ increase in BMI, there is an $85 \%$ increased odds of thromboembolic complications in these patients. Such conditions were also demonstrated in the obese patient by Frezza et al. ${ }^{19}$ Obesity is known to be a state that increases the chance of venous thromboembolism. Slower recovery, immobility, and being bedridden are some of the other reasons behind obesity and pro-thrombotic state. Similarly, Ho et al. found higher BMI to be one of the important risk factors for fatal PE in patients post trauma. $^{20}$ Other major risk factors identified were severity of injuries and existence of comorbidities in patients. It is the standard of care to categorize obese patients after trauma as high risk for thromboembolism (TE) and pulmonary embolus (PE) events and also to exercise preventive measurements, i.e. low molecular weight heparin (LMWH) and/or pneumatic compression as indicated.

In severe trauma patients, organ perfusion could be compromised for various reasons that would jeopardize a patient's life. It was demonstrated by Belzberg et al. that cardiac index was significantly lower in elderly and obese patients, which correlates with their survival. ${ }^{21}$ In order to prevent hypoxemia and tissue damage, patients were transfused with packed red blood cells (RBC) at a lower threshold. De Jong et al. demonstrated that obesity was directly related to a higher rate of massive transfusion ( $\geq 10 \mathrm{U}$ of packed RBC) even though the groups had similar trauma associated hemorrhage scores. ${ }^{22}$

\section{The effect of BMI in pediatrics trauma population}


Obesity in pediatric population is a topic that has been evaluated by some researchers since implications of childhood obesity on pediatric trauma have not been well studied. Witt et al. found in their study that obese children had a significantly longer length of stay in hospital and use of ventilators. ${ }^{23}$ They further showed higher BMI was associated with increased rate of pneumonia, DVT, PE, and mortality. Similarly, Rana et al. found that DVT and decubitus ulcers were higher in obese children. ${ }^{24}$ They found that obese children had higher rates of extremity fractures that required operative intervention, which placed them at a higher risk for complications (DVT and decubitus ulcers). Interestingly, they found lower incidence of intracranial and intra-abdominal injuries in obese children.

Pulmonary fat embolism (PFE) in pediatric trauma was the focus of study done by Eriksson et al. ${ }^{25}$ BMI was identified to be independently associated with increased PFE in children after trauma. Alselaim et al. evaluated the effects of obesity on trauma outcomes in the pediatric population. ${ }^{26}$ This study divided children by the $95^{\text {th }}$ percentile for BMI and found no significant association between obesity and mortality. The criteria used to separate the two groups may have included overweight or near obese patients in the control group leading to no observed difference in outcomes. However, this study reported a significant difference in the pattern of injury patients suffered among groups, obese vs non-obese groups. High BMI pediatric patients were more likely to sustain rib and pelvic fractures and to have higher Injury Severity Score (ISS) following trauma.

\section{The effect of BMI in injury patterns and recovery time}

Previous studies have shown obese patients suffer a distinct pattern of injury when compared to non-obese patients. Brown et al. identified that obese patients suffer fewer head injuries, but more chest and lower extremity injuries after trauma. ${ }^{27}$ Additionally, the obese group possessed significantly higher morbidity and mortality rates. Using stepwise regression analysis, authors revealed obesity to be an independent risk factor for mortality. Similarly, Pal et al. evaluated patients less than 60 years of age involved in MVCs from the side with no airbag deployment. Patients with increased BMI were not at increased risk for head injuries but were more likely to experience lower extremity injuries. ${ }^{28}$ Rupp et al. reported head-on MVCs to be associated with higher risk for lower and upper extremity injuries, as well as spinal injuries in obese patients. ${ }^{29}$ Obesity is associated with increased anterior abdominal fat content and as such, could serve as a protective factor for abdominal blunt and penetrating injuries. Bloom et al. evaluated chest and abdomen abbreviated injury scale (AIS).$^{30}$ Increased BMI was found to protect patients against abdominal stab wounds and to have lower need for an operation. Osborne et al. evaluated outcomes in obese patients who suffered penetrating injury, fall injury, and motor vehicle collisions (MVC). ${ }^{31}$ In this study, obese patients who were injured by falls and MVCs sustained fewer head injuries. The mortality rate was lowest in obese patients who had fall injury compared to the other two groups. The MVC group had a higher LOS in the hospital whereas penetrating trauma was associated with no difference in outcome. Obesity was concluded to be a protective factor in patients with falls. A retrospective study conducted by Evans et al. found that in older patients $(>45 \mathrm{yo})$, the BMI was associated with higher torso and proximal upper extremity injuries. ${ }^{32}$ However, BMI was not an independent risk factor for complications or 
mortality in older patients. Vincent et al. evaluated recovery time in patients suffering from orthopedic trauma by assessing functional independence measure (FIM), walking distance, and climbing stairs. ${ }^{33}$ Total and motor FIM scores were lower at discharge for obese patients. Moreover, even though improvement in FIM was seen using rehabilitation protocols, it was significantly at lower magnitude when compared to non-obese patients.

Motor vehicle collisions are one of the mainstays of morbidity and mortality in traumatic patients. Seatbelts and airbags have led to decrease in severity of injuries and deaths. In an attempt to find any significance in use of safety precautions by obese passengers, Joseph et al. determined mortality was 1.52 times higher in morbidly obese motorists. ${ }^{34}$ This was the same in the three study groups (non-restrained, seatbelt, seatbelt and airbag). The anatomy and physiology of the oropharynx in obese patients are different than in the non-obese. Interestingly Sifri et al. showed in their three-year long prospective study at a level I trauma center, that obesity was not a risk factor for intubation on patients. ${ }^{35}$ Nonetheless, higher BMI was associated with a statistically higher rate of early respiratory complications. The abdomen is one major area that injuries could occur. Two major organs, liver and spleen, are located in this area that could jeopardize patients' outcomes in a traumatic event. Vaughan et al. in a prospective study done in pediatric populations, tried to investigate the effect of obesity on abdominal injuries. ${ }^{36}$ They found that overall mean injury severity scale (ISS) and abdominal abbreviated injury score (AIS) were significantly higher in obese children. Most importantly they demonstrated that obese children suffered significantly higher liver lacerations (injury) than non-obese. They hypothesized this to be the result of hepatic steatosis that makes liver more prone to injury. Regardless of BMI, they found no difference in non-operative management of patients.

\section{The effect of BMI on the systemic inflammatory response and its associated comorbidities}

Inflammatory markers' association and function in response to trauma have been studied. Ciesla et al. performed a prospective study demonstrating an increase in multi organ failure (MOF) rate, using the Denver multiple organ failure score for obese patients compared to non-obese patients. ${ }^{37}$ Additionally, obesity was found to be an independent risk factor for the development of MOF. Obese patients were more likely to be admitted to the ICU and to have greater length of hospital stay. However, mortality was significantly increased in this group. Patient selection criteria excluded isolated head injuries, which may increase the mortality rate. This group theorizes that the constant heightened inflammatory state created by obesity leads to higher rate of MOF in the obese group. Similarly, Christmas et al. showed a four-fold increase in mortality rate for morbidly obese patients following trauma injury. ${ }^{38}$ Obese patients had a longer hospital stay and higher rate of MOF. The development of MOF was a significant risk factor for mortality in the obese patient group. To combat the development of MOF, Winfield et al. evaluated the novel use of angiotensin converting enzyme inhibitor (ACEI) and angiotensin receptor blockers (ARBs) in managing obese traumatic patients due to fundamental comprehension of obesity pathophysiology. ${ }^{39}$ In obese patients, angiotensin II (ATII) level was higher. Monocytes also contain ATII receptors on their surface and as a result are under direct influence of this system. Obese patients who received ACEI/ARBs not only showed improved T- 
cell function and monocyte maturation, but also demonstrated lower Marshall and Denver Scores for the development of MOF. The use of ACEI or ARBs in severely injured obese patients may represent a novel therapeutic target to improve outcomes following trauma injury.

Obesity leads to a chronically heightened inflammatory response. In a multicenter study done by Edmonds et al., outcome of patients suffering blunt injury who had hemorrhagic shock was evaluated. ${ }^{40}$ They found as BMI increased, rate of MOF also increased. This was mainly in cardiac, respiratory, and renal systems. They found for every increase of $1 \mathrm{~kg} / \mathrm{m} 2$ in BMI value, risk of MOF and nosocomial infections (NI) increased by $9 \%$ and $7 \%$ respectively. BMI was concluded to be an independent risk factor for MOF and NI.

\section{In-vitro and in-vivo trauma studies}

Diebel et al. attempted to assess how the role of gender impacts the adipocytes response to stress. ${ }^{41}$ Adipocytes were supplemented with either estrogen $\left(E_{2}\right)$ or testosterone (DHT) in-vitro and subsequently, exposed to epinephrine and hypoxia/re-oxygenation scenarios in order to emulate stress in-vivo. In the control group (no hormone exposure), the levels of tumor necrosis factor- $\alpha$ (TNF- $\alpha$ ) and interlukin-6 (IL-6) were increased following stress simulation. However, adipocytes exposed to physiologic levels of estrogen demonstrated decreased levels of TNF- $\alpha$ and IL-6 while adipocytes exposed to testosterone showed increased TNF- $\alpha$ and IL-6 levels similar to the control group. This dimorphism at the cellular level could help explain the differences in outcomes for obese patients following trauma in regards to gender.

Comorbidities associated with obesity such as metabolic syndrome and non-alcoholic fatty liver disease are found to be major risk factors for poor outcomes in obese patients following trauma. Matheson et al. explored this concept in small animal models. ${ }^{42}$ They demonstrated that obesity in rats impaired blood flow to the liver and kidneys, thus, leading to higher circulation of inflammatory markers (IL-1, IL-6, and human mobility group box-1(HMGB-1)). Additionally, obese rats suffered worse outcomes due to trauma regardless of injury severity. Traumatic injury worsened liver and renal functions in obese rats compared to the non-obese group.

\section{Conclusion}

Injuries from blunt trauma have always been a major cause of mortality and morbidity. Obesity on the other hand is a newer phenomenon that is on the rise. Careful examination of current literature can help to reveal the close impact of obesity in patients suffering blunt trauma. Obesity both as an independent factor (by presence of comorbidities), as well as directly by creating physical forces, affects outcome of patients undergoing blunt trauma. As presented in this literature, even though some conflicting results exist, the majority of publications show an intimate association between the two. Worse injury scale with specific patterns, higher ICU admissions, longer hospital stay, and higher mortality rates were amongst the observations in obese patients who suffered blunt trauma. This review also examined several studies that have attempted to shine light on this association by studying the pathophysiology of both obesity and trauma. One major finding is heightened inflammatory state created by obesity that plays a pivotal role in outcome of patients who have undergone trauma. Studying and analyzing this 
situation can have major implications with possible improvement in management strategies of patients at the scene as well as in the hospital.

\begin{tabular}{|c|c|}
\hline \multicolumn{2}{|r|}{ Abbreviations } \\
\hline ACEI & Angiotensin Converting Enzyme Inhibitor \\
\hline AIS & Abbreviated Injury Scale \\
\hline AKI & Acute Kidney Injury \\
\hline ARBs & Angiotensin Receptor Blockers \\
\hline ATII & Angiotensin-II \\
\hline BMI & Body Mass Index \\
\hline CAD & Coronary Artery Disease \\
\hline CVA & Cerebro Vascular Accident \\
\hline DHT & Dihydro testosterone (testosterone) \\
\hline DVT & Deep Venous Thrombosis \\
\hline ER & Emergency Room \\
\hline $\mathrm{E}_{2}$ & Estrogen \\
\hline FIM & Functional Independence Measurment \\
\hline GCS & Glasgow Coma Scale \\
\hline HMGB-1 & Human Mobility Group Box-1 \\
\hline HTN & Hypertension \\
\hline ICU & Intensive Care Unit \\
\hline IL-6 & Interleukin-6 \\
\hline ISS & Injury Severity Score \\
\hline LMWH & Low Molecular Weight Heparin \\
\hline LOS & Length of Stay \\
\hline MOF & Multi-organ Failure \\
\hline MVC & Motor Vehicle Collision \\
\hline NI & Nosocomial Infection \\
\hline NIS & National Institute of Health \\
\hline $\mathrm{PE}$ & Pulmonary Embolism \\
\hline PFE & Pulmonary Fat Embolism \\
\hline RBC & Red Blood Cells \\
\hline SBP & Systolic Blood Pressure \\
\hline TAC & Temporary Abdominal Closure \\
\hline TE & Thromboembolism \\
\hline TNF- $\alpha$ & Tissue Necrosis Factor- $\alpha$ \\
\hline
\end{tabular}




\section{References}

1. Ogden CL, Carroll MD, Kit BK, Flegal KM. Prevalence of obesity and trends in body mass index among US children and adolescents, 1999-2010. JAMA. 2012;307(5):483-90.

2. Flegal KM, Carroll MD, Kit BK, Ogden CL. Prevalence of obesity and trends in the distribution of body mass index among US adults, 1999-2010. JAMA. 2012;307(5):491-7.

3. Finkelstein EA, Chen H, Prabhu M, Trogdon JG, Corso PS. The relationship between obesity and injuries among U.S. adults. Am J Health Promot. 2007;21(5):460-8.

4. Hoffmann M, Lefering R, Gruber-Rathmann M, Rueger JM, Lehmann W, Trauma Registry of the German Society for Trauma S. The impact of BMI on polytrauma outcome. Injury. 2012;43(2):184-8.

5. Bochicchio GV, Joshi M, Bochicchio K, Nehman S, Tracy JK, Scalea TM. Impact of obesity in the critically ill trauma patient: a prospective study. J Am Coll Surg. 2006;203(4):533-8.

6. Ditillo M, Pandit V, Rhee P, Aziz H, Hadeed S, Bhattacharya B, et al. Morbid obesity predisposes trauma patients to worse outcomes: a National Trauma Data Bank analysis. J Trauma Acute Care Surg. 2014;76(1):176-9.

7. Alban RF, Lyass S, Margulies DR, Shabot MM. Obesity does not affect mortality after trauma. Am Surg. 2006;72(10):966-9.

8. Diaz JJ, Jr., Norris PR, Collier BR, Berkes MB, Ozdas A, May AK, et al. Morbid obesity is not a risk factor for mortality in critically ill trauma patients. J Trauma. 2009;66(1):226-31.

9. Childs BR, Nahm NJ, Dolenc AJ, Vallier HA. Obesity Is Associated With More Complications and Longer Hospital Stays After Orthopaedic Trauma. J Orthop Trauma. 2015;29(11):504-9.

10. Dhungel V, Liao J, Raut H, Lilienthal MA, Garcia LJ, Born J, et al. Obesity delays functional recovery in trauma patients. J Surg Res. 2015;193(1):415-20.

11. Johnston M, Safcsak K, Cheatham ML, Smith CP. Management of the Open Abdomen in Obese Trauma Patients. Am Surg. 2015;81(11):1134-7.

12. Bonizzoli M, Zagli G, Lazzeri C, Degl'Innocenti S, Gensini G, Peris A. Early insulin resistance in severe trauma without head injury as outcome predictor? A prospective, monocentric pilot study. Scand J Trauma Resusc Emerg Med. 2012;20:69.

13. Glance LG, Li Y, Osler TM, Mukamel DB, Dick AW. Impact of obesity on mortality and complications in trauma patients. Ann Surg. 2014;259(3):576-81.

14. Livingston DH, Lavery RF, N'Kanza A, Anjaria D, Sifri ZC, Mohr AM, et al. Obesity does not increase morbidity and mortality after laparotomy for trauma. Am Surg. 2013;79(3):247-52.

15. Serrano PE, Khuder SA, Fath JJ. Obesity as a risk factor for nosocomial infections in trauma patients. J Am Coll Surg. 2010;211(1):61-7.

16. Chan JL, Imai T, Barmparas G, Lee JB, Lamb AW, Melo N, et al. Rhabdomyolysis in obese trauma patients. Am Surg. 2014;80(10):1012-7.

17. Shashaty MG, Meyer NJ, Localio AR, Gallop R, Bellamy SL, Holena DN, et al. African American race, obesity, and blood product transfusion are risk factors for acute kidney injury in critically ill trauma patients. J Crit Care. 2012;27(5):496-504.

18. Kornblith LZ, Howard B, Kunitake R, Redick B, Nelson M, Cohen MJ, et al. Obesity and clotting: Body mass index independently contributes to hypercoagulability after injury. J Trauma Acute Care Surg. 2015;78(1):30-6; discussion 7-8.

19. Frezza EE, Chiriva-Internati M. Venous thromboembolism in morbid obesity and trauma. A review of literature. Minerva Chir. 2005;60(5):391-9.

20. Ho KM, Burrell M, Rao S, Baker R. Incidence and risk factors for fatal pulmonary embolism after major trauma: a nested cohort study. Br J Anaesth. 2010;105(5):596-602.

21. Belzberg H, Wo CC, Demetriades D, Shoemaker WC. Effects of age and obesity on hemodynamics, tissue oxygenation, and outcome after trauma. J Trauma. 2007;62(5):1192-200.

22. De Jong A, Deras P, Martinez O, Latry P, Jaber S, Capdevila X, et al. Relationship between Obesity and Massive Transfusion Needs in Trauma Patients, and Validation of TASH Score in Obese Population: A Retrospective Study on 910 Trauma Patients. PLoS One. 2016;11(3):e0152109.

23. Witt CE, Arbabi S, Nathens AB, Vavilala MS, Rivara FP. Obesity in pediatric trauma. J Pediatr Surg. 2016.

24. Rana AR, Michalsky MP, Teich S, Groner JI, Caniano DA, Schuster DP. Childhood obesity: a risk factor for injuries observed at a level-1 trauma center. J Pediatr Surg. 2009;44(8):1601-5.

25. Eriksson EA, Rickey J, Leon SM, Minshall CT, Fakhry SM, Schandl CA. Fat embolism in pediatric patients: an autopsy evaluation of incidence and etiology. J Crit Care. 2015;30(1):221 e1-5. 
26. Alselaim N, Malaekah H, Saade M, Hussein M, Altokhais T, Albedah K, et al. Does obesity impact the pattern and outcome of trauma in children? J Pediatr Surg. 2012;47(7):1404-9.

27. Brown CV, Neville AL, Rhee P, Salim A, Velmahos GC, Demetriades D. The impact of obesity on the outcomes of 1,153 critically injured blunt trauma patients. J Trauma. 2005;59(5):1048-51; discussion 51.

28. Pal C, Tomosaburo O, Vimalathithan K, Jeyabharath M, Muthukumar M, Satheesh N, et al. Effect of weight, height and BMI on injury outcome in side impact crashes without airbag deployment. Accid Anal Prev. 2014;72:193-209.

29. Rupp JD, Flannagan CA, Leslie AJ, Hoff CN, Reed MP, Cunningham RM. Effects of BMI on the risk and frequency of AIS 3+ injuries in motor-vehicle crashes. Obesity (Silver Spring). 2013;21(1):E88-97.

30. Bloom MB, Ley EJ, Liou DZ, Tran T, Chung R, Melo N, et al. Impact of body mass index on injury in abdominal stab wounds: implications for management. J Surg Res. 2015;197(1):162-6.

31. Osborne Z, Rowitz B, Moore H, Oliphant U, Butler J, Olson M, et al. Obesity in trauma: outcomes and disposition trends. Am J Surg. 2014;207(3):387-92; discussion 91-2.

32. Evans DC, Stawicki SP, Davido HT, Eiferman D. Obesity in trauma patients: correlations of body mass index with outcomes, injury patterns, and complications. Am Surg. 2011;77(8):1003-8.

33. Vincent HK, Seay AN, Vincent KR, Atchison JW, Sadasivan K. Effects of obesity on rehabilitation outcomes after orthopedic trauma. Am J Phys Med Rehabil. 2012;91(12):1051-9.

34. Joseph B, Hadeed S, Haider AA, Ditillo M, Joseph A, Pandit V, et al. Obesity and trauma mortality: Sizing up the risks in motor vehicle crashes. Obes Res Clin Pract. 2017;11(1):72-8.

35. Sifri ZC, Kim H, Lavery R, Mohr A, Livingston DH. The impact of obesity on the outcome of emergency intubation in trauma patients. J Trauma. 2008;65(2):396-400.

36. Vaughan N, Tweed J, Greenwell C, Notrica DM, Langlais CS, Peter SD, et al. The impact of morbid obesity on solid organ injury in children using the ATOMAC protocol at a pediatric level I trauma center. J Pediatr Surg. 2017;52(2):345-8.

37. Ciesla DJ, Moore EE, Johnson JL, Burch JM, Cothren CC, Sauaia A. Obesity increases risk of organ failure after severe trauma. J Am Coll Surg. 2006;203(4):539-45.

38. Christmas AB, Reynolds J, Wilson AK, Franklin GA, Miller FB, Richardson JD, et al. Morbid obesity impacts mortality in blunt trauma. Am Surg. 2007;73(11):1122-5.

39. Winfield RD, Southard RE, Turnbull IR, Bochicchio K, Reese S, Freeman BD, et al. Angiotensin Inhibition Is Associated with Preservation of T-Cell and Monocyte Function and Decreases Multiple Organ Failure in Obese Trauma Patients. J Am Coll Surg. 2015;221(2):486-94 e4.

40. Edmonds RD, Cuschieri J, Minei JP, Rosengart MR, Maier RV, Harbrecht BG, et al. Body adipose content is independently associated with a higher risk of organ failure and nosocomial infection in the nonobese patient postinjury. J Trauma. 2011;70(2):292-8.

41. Diebel ME, Diebel LN, Liberati DM. Gender dimorphism in adipose tissue response to stress conditions: A plausible mechanism to explain the conflicting data regarding trauma and obesity. J Trauma Acute Care Surg. 2016;81(6):1028-34.

42. Matheson PJ, Franklin GA, Hurt RT, Downard CD, Smith JW, Garrison RN. Direct peritoneal resuscitation improves obesity-induced hepatic dysfunction after trauma. J Am Coll Surg. 2012;214(4):517-28; discussion 28-30. 